\title{
Misinformation, Stereotypes and Perceptions of Institutions: The Perspective of Young Italians on Immigration after the "Shootings in Macerata"
}

\author{
Giacomo Buoncompagni \\ University of Macerata, Macerata, Italy \\ Email: giacomo.buoncompagni@libero.it
}

How to cite this paper: Buoncompagni, G. (2021). Misinformation, Stereotypes and Perceptions of Institutions: The Perspective of Young Italians on Immigration after the "Shootings in Macerata". Open Journal of Political Science, 11, 215-233. https://doi.org/10.4236/ojps.2021.112014

Received: December 20, 2020

Accepted: February 28, 2021

Published: March 3, 2021

Copyright ( 2021 by author(s) and Scientific Research Publishing Inc. This work is licensed under the Creative Commons Attribution International License (CC BY 4.0).

http://creativecommons.org/licenses/by/4.0/

(c) (i) Open Access

\begin{abstract}
The errors of journalistic information on the topic of immigration are mainly those of its public representation enclosing the continuous attempt to define an "old" phenomenon as an unprecedented and current problem. The consequence of a still "undisciplined" journalism on this issue is the strengthening of the common sense of xenophobic prejudice driven by two phenomena that are increasingly affecting digital platforms: online (mis)information (fake news and information overload) and hate speech. For the purpose of the research, among the episodes of online violence that emerged and highlighted in the literature, it was considered important to dwell on an interesting case of analysis concerning the perception of the migration phenomenon in relation to the role of digital media and the narrative modalities used to influence public opinion through stereotypes and prejudices. In addition, an attempt was made to understand how young university students judge migration policies and the behaviour of institutions towards this issue. The study highlighted which social constructions of immigration have most permeated the target population and influenced their way of using traditional and digital media, as well as the elaboration of communication strategies and policies adopted by local, national and European institutions in the field of immigration.
\end{abstract}

\section{Keywords}

Digital Media, Migration, Perception, Journalism, Macerata, Italy

\section{Introduction}

The securitisation of the immigrant and the tendency to represent him or her as 
a victim or criminal are two common elements in the media narrative in many countries of transit or arrival; the process of criminalisation of the immigrant is closely linked to the extent of the migratory flows that the globalisation of the economy and culture have fuelled over the years (Beck, 2006; Bauder, 2011).

The centrality of the news concerning the crimes of immigrants appears as an attempt to remove the tiring "conflict-integration" debate in order to give space to a more reassuring discussion on the topic of the Other as a "threat"; according to Palidda (2011), the criminalization of the foreigner, understood as a set of speeches, facts and practices performed by the police, judicial authorities, but also by local administrations, media, is a common aspect in many European countries and not only.

However, there is no arithmetic relationship between the increase in resident immigrants and the changes in crime rates: the link between collective anxiety, crime and media narrative tends to be homogeneous in countries with different cultures and histories (Kymlicka, 2012).

In particular, after September 11, 2001, a process of radicalisation of conflict cultures has started that has generated a close link between immigrant presence, multicultural cohabitation and illegal activities, from petty crime to terrorism (Orsini, 2019); the regular emergence, within the public debate, of an "ethnicization" of crime, indicates a cultural reaction to otherness, a sort of conditioned reflex, which tends to replicate itself in a very similar way in distant cultural contexts.

Also, ethnic and religious minorities are often subject to processes of discrimination; in fact, another distorted representation of otherness concerns the criminalization of the Romanian population, i.e. the tendency, in countries of the Balkan area and in European countries such as Italy, to describe members belonging to this minority as "criminals par excellence" through a discriminatory media narrative that contributes to fuel waves of moral panic and the idea of immigration as a synonym of disorder and malaise.

Even in Japan, a country with a strong ethnic homogeneity, the growth in the number of immigrants has generated a sense of insecurity and attitudes of distrust, a consequence of the idea that immigrants, especially illegal immigrants, are prone to deviance and crime.

What we are witnessing, quoting Walter Lippmann (1922), is a "reduction of complexity", a process of simplification, the activation of mechanisms on which the dominant public discourse is based.

The limitations of journalistic information on the theme of immigration are above all those of its public representation enclosing the continuous attempt to define an "old" phenomenon as an "unprecedented and current problem" or in the ineffective and contradictory migration policies proposed and implemented in the last thirty to forty years.

Istat data and those of the Ministry of Justice in Italy suggest that there is a massive presence of immigrants in Italian prisons (Orsini, 2019; Buoncompagni, 
2019).

Foreigners, in Italy, represent only $10 \%$ of the population and the crimes in which they are most involved, such as drugs, rape, theft, robbery, are "particularly hateful for the common man because they have a negative impact on the quality of his daily life" (Orsini, 2019: p. 88).

The sociologist Raymond Boudon explains how, according to the situation in which they find themselves, anti-immigrants seem totally rational when wanting to remove what puts their daily life at risk and if they believe that the high number of landings or immigrants present in their country put their health or jobs at serious risk, it is rational for them to ask for their expulsion.

Human beings put in the first place consider the reality of direct encounter and one could approach the situation described so far to an attitude defined as "streetlight effect", a type of communicative-behavioral distortion linked to the human tendency to conduct the search for truth through simple ways, avoiding complexity.

The alarmist and anxiety-ridden news reports have increased over the years and there has been a return to talking about immigration in relation to specific news (black and judicial) since 2017, the pre-election year in Italy. As a result, the political agenda has also had a strong impact on how to combine and connect news, and citizens' fears, fuelled by an idea of politics based on the search for an easy and immediate consensus, have been met.

The consequence of a still "undisciplined" journalism on the issue is the strengthening of the common sense of xenophobic prejudice driven by two phenomena that are increasingly affecting digital platforms: online misinformation (and information overload) and hate speech.

The most recent literature (Giddens, 2002; Ziccardi, 2016; Gillespie, 2018) explores the problem of online violence in relation to the ability of digital technology to promote new discriminatory and intolerant behaviours (e.g. racial, ethnic, religious, gender or sexual orientation), linked to the phenomenon of hate or ad personam hatred. The aim of this paper is therefore to focus on an interesting case analysis concerning the perception of the migration phenomenon in relation to the role of digital media and the narrative modes used to influence public opinion through stereotypes and prejudices. We tried to understand how young university students in the city of Macerata (Italy), protagonist of a shooting against foreign citizens, judge migration policies and institutions' behaviour towards this issue. The study highlighted which social constructions of immigration have most permeated the target population and influenced the way they use traditional and digital media, as well as the elaboration of communication strategies and policies adopted by local, national and European institutions in the field of immigration.

\section{Methodology and Research Objectives}

For the purpose of the research, among the episodes of online violence that 
emerged and were highlighted in the literature, it was considered important to dwell on an interesting case of analysis concerning the perception of the migration phenomenon in relation to the role of digital media and the narrative methods used to influence public opinion through stereotypes and prejudices. In addition an attempt was made to understand how young university students judge migration policies and the behaviour of institutions towards this issue. The study highlighted which social constructions of immigration have most permeated the target population and influenced their way of using traditional and digital media, as well as the elaboration of communication strategies and policies adopted by local, national and European institutions in the field of immigration. The method used was that of the online questionnaire.

It should be pointed out that the period of construction of the questionnaire coincided with what the media called "the facts of Macerata" or "shootings in Macerata" (February 3, 2018), meaning by this expression the attack by Luca Traini (which took place in the city of Macerata (Marche, Italy), whose victims were exclusively foreign citizens) and the murder of the young Pamela Mastropietro (another criminal event occurred in the same period).

Both episodes took place in the first months of the year 2018 in the province of Macerata, Marche, Italy (Affricott, 2018).

A local Italian case, which later became national and was later reported by international quotaholders (France, Germany, Spain, United Kingdom and United States).

In the months that followed there were many political events and debates that were the subject of a permanent electoral campaign and that involved citizens and institutions on the subject in the Marche Region; in addition to these political-media elements, it is necessary to highlight how the Region itself is to be considered a "strategic" territory for analysis and observation.

The questionnaire, in Italian, was created using the SurveyMonkey platform, a technique for compiling online interviews/forms that is particularly useful when it comes to examining self-selected, non-statistically representative samples of the population.

The questionnaire was administered at the end of February 2018 and remained online for two months.

The sample of people who filled in the questionnaire online was not random, but it was partly self-selected since people participated on a voluntary basis; at the same time, in order to make the survey more structured and targeted, some teachers from every Department of the University of Macerata were asked to make public the link generated online on their personal web page.

In agreement with students and professors, it was decided to organize short targeted meetings for the presentation of the research, in order to explain the characteristics and objectives of the project, providing short theoretical notions on the issues related to the theme "media, immigration and institutions".

The questionnaire was filled in by young students $(21.09 \%$ male and $78.91 \%$ 
female), the emerging age groups were those between 18 and 22 years old (58.91\%) and 23 - 26 years old (22.91\%), most of them born in Italy (93.82\%).

All students were from Macerata, the place of origin of the violence.

The sample survey has enabled us to understand which social constructions of immigration have permeated the reference student population the most, evaluating in parallel their relationship with the media and information, as well as their perception on the effectiveness of migration policies and communication strategies implemented by national and European institutions.

The questionnaire included open-ended and multiple-choice questions and was structured in four parts.

The first part focused mainly on the use of traditional and digital media and the relationship of the sample with information, while the second part focused on the migration phenomenon in Italy and its representation in the main information channels; the third part included questions on the role of institutions in the management of migration flows and communication on the same topic, and finally the section dedicated to socio-demographic data.

As stated before, the period of construction of the questionnaire coincided with what the media defined as "the facts of Macerata", whose victims were exclusively foreign citizens.

In the following months there were many events and political debates that were the subject of a permanent electoral campaign involving the citizens and institutions on the topic of migrants in the Marche Region, in particular in the province of Macerata; in this regard the main limitation of this second part of the exploratory phase of the research can be identified, even if in a small part, just in the period of time in which the questionnaire was administered to students, in conjunction with the "facts of Macerata".

A large part of the sample is resident in the Marche region, mostly students enrolled at the University of Macerata (63.27\%), who are also involved in extra-university activities in the area and for these reasons the degree of emotional involvement may have somehow influenced the answer to some of the questions asked.

In spite of this, it was also possible to identify strengths that should not be underestimated, i.e., for example, the good level of participation, seriousness and interest that the students showed during the administration of the questionnaire during the subsequent teaching and seminar activities that have involved the whole University in recent years on the subject of media and migration processes.

\section{3. (Mis)Information and Social Use of Media}

The survey opens with some questions about the relationship between youth, information and traditional and digital media. The language used was Italian (with English in note).

"Do you think it is useful to inform yourself today?" "Which media do you use most?" "Have you ever compared different sources of information on the 
same subject?" "Do you have confidence in the media?"

The first part of the investigation tried to answer these questions, the choice to investigate this specific issue, right at the beginning, was twofold.

The first is linked to the emergence of a recent socio-informative phenomenon that is rather new in digital environments, the so-called fake news, which has upset the way of producing, reading and interpreting information, especially online information, in the last five years.

At the end of 2016, with the referendum on Brexit and the election of US President Donald Trump, the most debated issue was that of misinformation online and in traditional channels.

The expression fake news refers to that type of plausible information, based on distorted or non-existent data, whose purpose is to deceive and even manipulate the reader the effectiveness of false news is due firstly to its ability to appear plausible, secondly to its ability to capture the attention of the recipients, exploiting immediate and easy to arouse emotions and leveraging the prejudices spread within a social fabric (Quattrociocchi \& Vicini, 2017).

The media logics of spectacularization guarantee the functioning of this manipulation process especially if activated within digital environments, where the information and public overload make a healthy comparison with other more complex information sources, while, as seen in the previous analysis, they facilitate hypersensitive and intolerant attitudes and adherence to stereotypes and prejudices.

Moreover, drawing inspiration from the literature on the subject and the reports published in the years 2017-2018 (the year in which the research presented here began), the Italian youth population was the one most linked to a high level of media consumption compared to the elderly, and this was the second main motivation.

Starting from this general scenario, the results that emerged from the questionnaire immediately proved to be interesting.

To the question "Do you think it is useful to inform yourself?" (Figure 1) and "why? (Figure 2)" $83.65 \%$ of the interviewees replied that they consider it very useful because it "serves to develop autonomous and critical thinking awareness" (70.83\%) while $14.42 \%$ consider it quite useful and see information as a "tool to defend oneself against manipulators" (11.86\%), 7.05\% think it is a way to enrich oneself from a cultural point of view.

The type of information that is mainly followed is culture (67.31\%), followed by news $(46.79 \%)$ and politics (34.94\%); particularly interesting (considering the research work presented below) is to see how a significant part of students follow the news at a local level (32.37\%) as well as the news and gossip, while less attention is paid to science and technology issues (Figure 3).

Connected to this data follow other responses that have been particularly significant in understanding how young students relate to traditional and digital information channels (Table 1). 


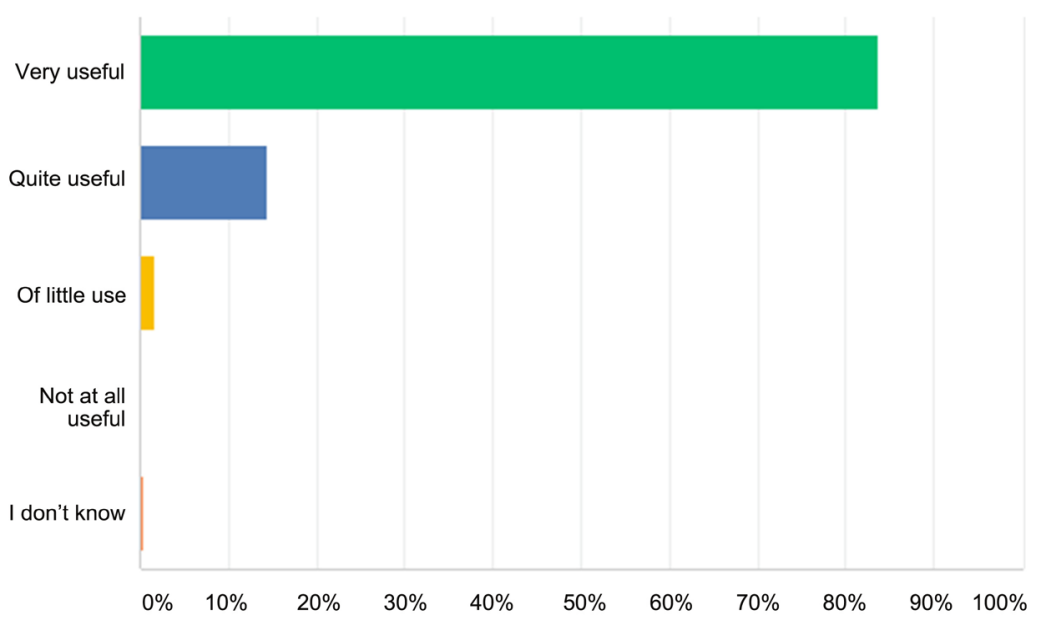

Figure 1. Do you think it is useful to inform yourself?

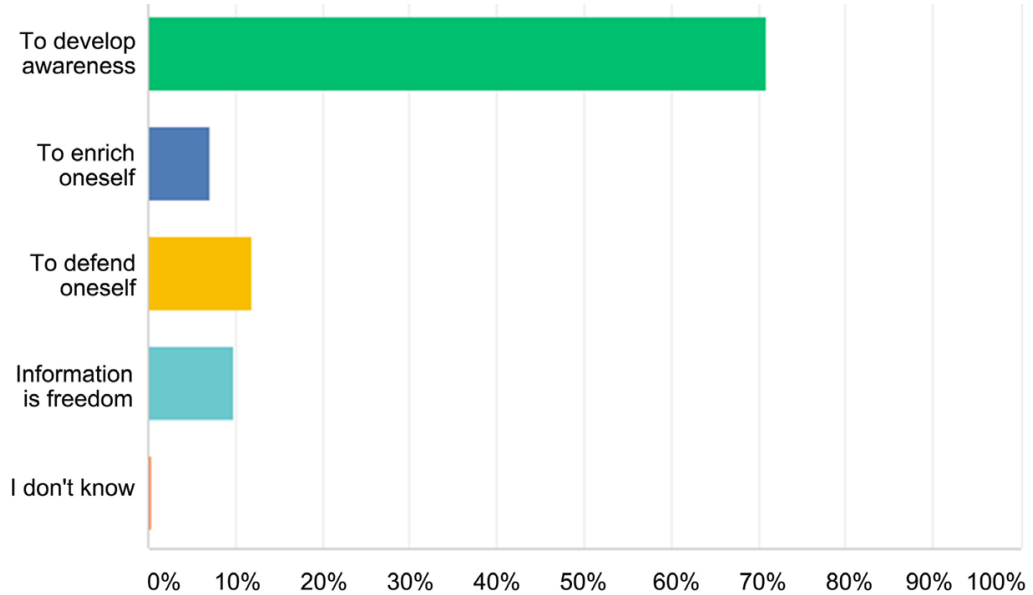

Figure 2. Why?

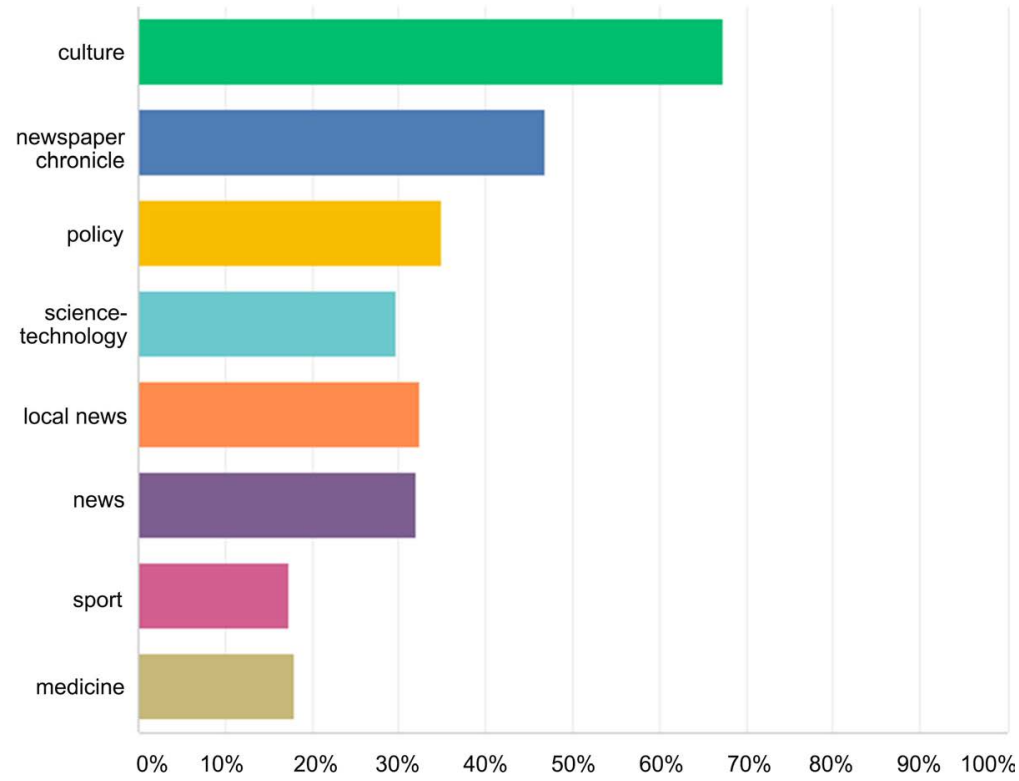

Figure 3 . What kind of information are you mainly interested in ?** $^{*}$ 
Table 1. Thinking about your experience, how often do you use the following means to inform yourself?

\begin{tabular}{ccccc}
\hline medium & never & rarely & Often & always \\
\hline Read newspapers & $18.97 \%$ & $54.98 \%$ & $23.47 \%$ & $2.57 \%$ \\
See the news & $4.19 \%$ & $18.71 \%$ & $47.42 \%$ & $29.68 \%$ \\
Listen to the radio & $12.58 \%$ & $26.13 \%$ & $40.65 \%$ & $20.65 \%$ \\
Visit websites & $2.89 \%$ & $19.61 \%$ & $52.41 \%$ & $25.08 \%$ \\
Use Facebook & $4.50 \%$ & $15.76 \%$ & $25.08 \%$ & $54.66 \%$ \\
Use Twitter & $86.13 \%$ & $6.45 \%$ & $4.19 \%$ & $3.23 \%$ \\
Use Youtube & $4.52 \%$ & $19.03 \%$ & $46.45 \%$ & $30.00 \%$ \\
Use Instagram & $15.48 \%$ & $5.81 \%$ & $7.10 \%$ & $71.61 \%$ \\
Use Linkedin & $86.41 \%$ & $8.41 \%$ & $2.59 \%$ & $2.59 \%$ \\
Read or write in blogs/forums & $57.88 \%$ & $27.65 \%$ & $11.25 \%$ & $3.22 \%$ \\
\hline
\end{tabular}

To the question "Thinking about your experience, how often do you use the following means to inform yourself?", considering the different media proposed as answer options, we notice a rather important proportion, in percentage terms, of people who do not use Twitter (86.13\%), Linkedin (86.41\%), Blog/Forum (57.88\%). More frequent instead is listening to the radio (40.65\%) and watching the news (47.42\%); it should be noted that in general the most popular digital spaces are Facebook (54.66\%) and Instagram (71.61\%).

Relevant results also in this case were found in the following question "Have you ever compared different sources on the same subject to verify the news?" where $80.13 \%$ say they compare news dealing with the same subject, $15.38 \%$ do not usually proceed with this verification operation (Figure 4).

Similar data also emerged from a recent research carried out in Italy by Skuola.net on 3500 users of the portal on behalf of the State Police during the event "Una Vita da Social" (2017), the initiative for the education to the correct use of the Net, where $93 \%$ of young people between the age of 11 and 25 declared that they verify the information and know how to distinguish between fake news and real news.

The habit of verifying sources, on the part of young people, constitutes a real "strategic competence" linked to the use of new media and falling within the concept of media literacy defined as the ability to access, analyse, evaluate and produce messages in all media communication formats.

As Van Dijk (2003) and Prensky (2013) recall, in addition to the more basic operational skills already found in the "digital natives", there is a need for a greater ability to manage relational wealth/overabundance on the web and to select and process information (informational skills). Furthermore the awareness on the part of the interviewees that the media environment (Table 2), especially the digital one, mainly hosts news that turns out to be false or difficult to verify, can be seen in the fair level of trust they place in the media. 


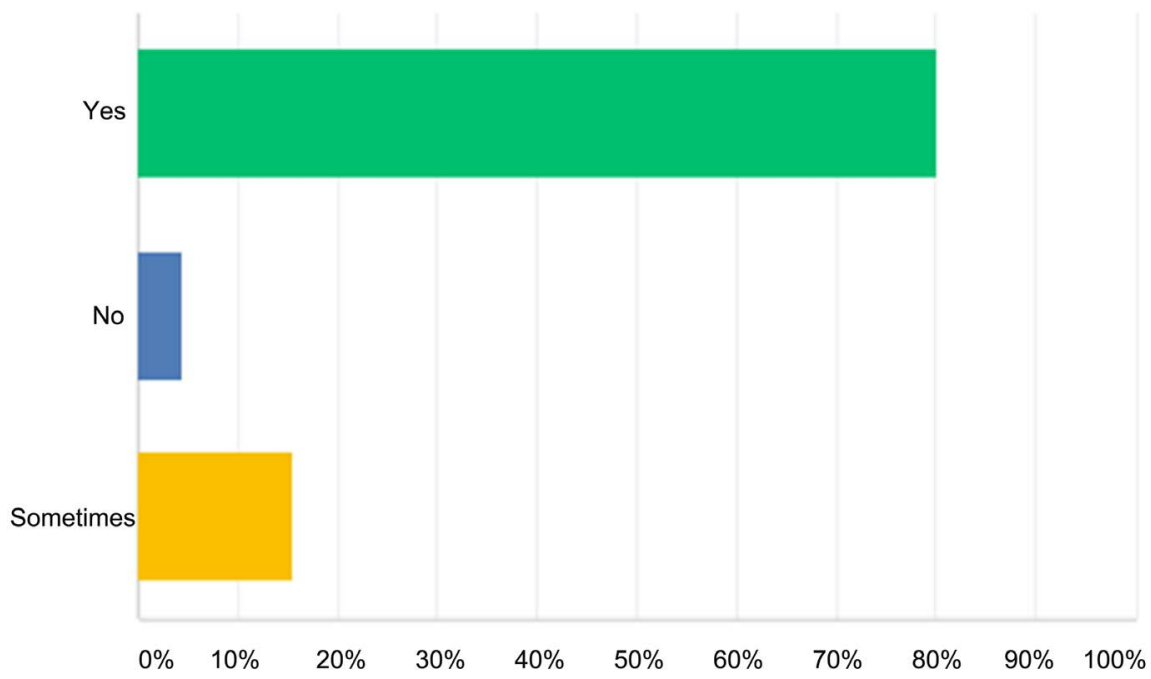

Figure 4. Have you ever compared different sources on the same subject in order to verify the news?**

Table 2. Do you trust the following media?

\begin{tabular}{cccccc}
\hline medium & none & little & Enough & a lot & I don't know \\
\hline Magazine-newspapers & $1.28 \%$ & $15.71 \%$ & $62.18 \%$ & $19.23 \%$ & $1.60 \%$ \\
News & $3.85 \%$ & $22.76 \%$ & $52.24 \%$ & $20.83 \%$ & $0.32 \%$ \\
Radio & $2.57 \%$ & $15.43 \%$ & $61.09 \%$ & $17.04 \%$ & $3.86 \%$ \\
Websites & $1.28 \%$ & $24.04 \%$ & $56.09 \%$ & $16.67 \%$ & $1.92 \%$ \\
Blog/forum & $9.94 \%$ & $44.23 \%$ & $34.29 \%$ & $2.56 \%$ & $8.97 \%$ \\
Youtube & $8.97 \%$ & $35.90 \%$ & $42.95 \%$ & $5.77 \%$ & $6.41 \%$ \\
Facebook & $10.61 \%$ & $53.70 \%$ & $29.26 \%$ & $3.54 \%$ & $2.89 \%$ \\
Twitter & $25.00 \%$ & $30.19 \%$ & $19.48 \%$ & $3.90 \%$ & $21.43 \%$ \\
Instagram & $16.18 \%$ & $38.83 \%$ & $27.83 \%$ & $4.85 \%$ & $12.30 \%$ \\
\hline
\end{tabular}

What emerges in this regard from the survey carried out among students is that, considering the higher response rates, $62.18 \%$ of respondents state that they have "enough" confidence in the daily paper press, the news (52.24\%) and also in radio $(61.09 \%)$.

The levels of trust are lower if we look at digital channels: $44.23 \%$ consider what is written and seen in blogs or forums, as well as YouTube (35.90\%), Facebook $(53.70 \%)$ and Instagram (38.83\%) to be "not very reliable", while official online news sites are those most consulted and considered "fairly reliable" (56.09\%).

The greatest confidence can be seen in the traditional media, news and print headlines.

The technological risks discussed in the previous chapter, hate speech and fake news in particular, have contributed to a less credible digital environment in recent years. 
Since 2016, there have been peaks of distrust of content shared within social media.

This is also demonstrated by a recent Italian study entitled "How to inform the new Italian generations" conducted by the Demopolis Institute on behalf of the Order of Italian Journalists, which highlights how the under-30s in Italy use the online press $(75 \%)$, but also television (66\%), as their primary information tool.

The under-30s in Italy place greater trust in social networks, $63 \%$ use Facebook or YouTube to keep themselves informed, but this is not blind trust; 56\% of them, in fact, draw on social news with a critical spirit, often doubting the real credibility of such news.

Trust in the credibility of the news rises, but if you rely on traditional media, only $24 \%$ say they often doubt the credibility of television or print media.

The results of our questionnaire on this aspect also coincide to a large extent with the data published in the 2018 Censis Report, where we read how, in the media ranking, Italians use the news and Facebook to inform themselves, but while the news media are strengthening their function (their audience increases from $60.6 \%$ in 2017 to $65 \%$ in 2018), Facebook has suffered a major setback $(-9.1 \%)$.

We are witnessing a drop in the use of online channels that has affected not only social networks, such as YouTube $(-5.3 \%)$ and Twitter $(-3 \%)$, but also the web in general (search engines lost $7.8 \%$ of users for information purposes). In terms of trust, the radio has achieved the primacy of credibility, with $69.7 \%$ of Italians considering it "very reliable".

In the trend towards loss of confidence, digital media stand out, the new platforms become vehicles for news subject to possible manipulation and the result is that $27.2 \%$ of Italians trust social networks less and $20.7 \%$ have less confidence in online news sites.

\section{Immigration and Its Representation}

In the second part of the questionnaire, after having investigated student's relationship with the media, the questions proposed to the students aimed at understanding their knowledge and perception of the migration phenomenon on the basis of the political and media narrative to which they are exposed daily.

First of all, the open question, "Who is the immigrant for you?" was administered, trying to assess whether the answers then gave came from a socio-legal or cultural knowledge base of immigration or from a sum of definitions/common places found in the main Italian media.

The answers, which were rather numerous and varied, have been traced back to 4 interpretative macro-categories containing the most significant definitions provided by the sample: 1) immigrant as a different subject, is an individual who moves because he is forced to leave the contexts of poverty in which he lives, to escape situations of violence (e.g. "needy person who runs away", "person who 
lives in a country of war", "desperate person who puts himself at stake"); 2) immigrant as a foreigner, he is a nomadic person, of different language, with his own customs and habits (e.g. "person who comes from another country", "he who moves", "who has different origins"); 3) immigrant as "new citizen", he is the one who moves with the aim of building a future outside his country of origin and builds new relationships (e.g. "person who changes country to live better", "person who looks for work outside", "person looking for a welcome and good opportunities"); 4) immigrant as "Person", as an individual who cannot be defined exclusively according to ethno-legal or socio-cultural categories (e.g. "a human being", "man and citizen of the world") (Figure 5).

According to the definition proposed by the UN, "immigrant" is someone who has moved to a country other than his usual residence and who has lived in that country for more than a year (Ambrosini, 2011).

What emerges from the survey presents common traits with this definition, considering that the immigrant is however understood by the interviewees as a subject in continuous movement, generally of a different culture, who moves because driven by needs of various kinds to settle in another place in a more or less definitive way.

The interviewees also believe that the presence of immigrants in Italy is a "stimulus for greater social inclusion" (39.57\%) and "an opportunity for greater socialization and urban regeneration" (30.94\%), although the fact that $15.83 \%$ believe that the immigrant is "a obstacle for the community" should not be underestimated (Figure 6).

On the basis of these data, it is useful to notice how a "neutral" vision of the migrant emerges, however without stereotypes or prejudices, unlike what it has been possible to find in the public discourse within social networks as shown in the previous chapter.

This vision is difficult to find in the media, where the figure of the immigrant is still the victim of communicative stereotypes: more than half of the interviewees consider the information on the migrants' issue in the main media as "unsatisfactory" (53.96\%), while $21.94 \%$ do not think that the information we have

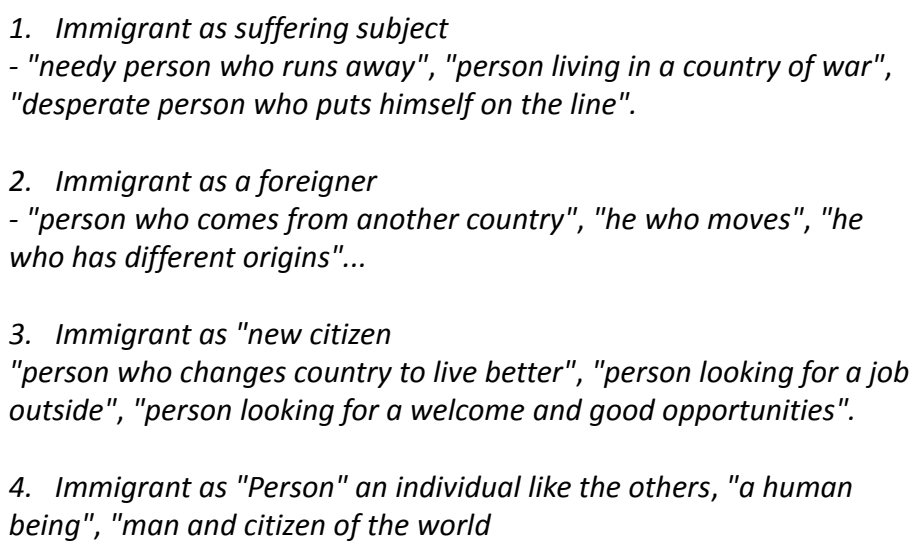

Figure 5. Interpretative categories of immigrant. 


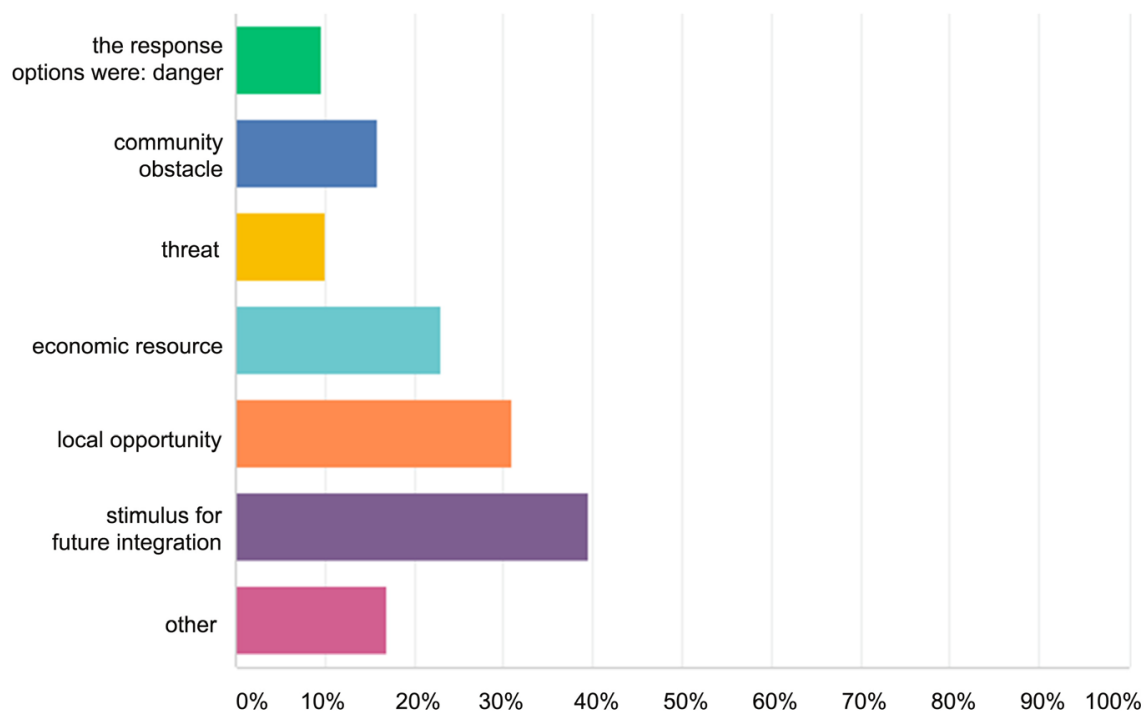

Figure 6. In Italy immigrants represent.

available is useful to better understand the immigration phenomenon (Figure 7).

This is not surprising when one considers, proceeding with the survey, that the digital platforms Facebook (79.14\%) and Instagram (33.81\%), for example, are considered communication spaces where a higher level of verbal violence and false news can be found. This is followed by television (34.17\%) and online information sites (30.58\%) (Figure 8).

As pointed out, the interviewees have a fair amount of confidence in digital media and believe that the current information does not provide a clear and exhaustive narration of the migration phenomenon, on the contrary, they believe that communication is falsified, confused and violent.

Phenomena such as those of online buffaloes are considered rather harmful to society, especially they believe that we have increased the level of insecurity in our country (52.52\%), increasing distrust between information systems and citizens (37.05\%) and favouring the criminalization of foreigners (35.25\%).

A very low percentage of the sample (1.08\%) does not believe that these online phenomena have had an important impact on society (Figure 9).

At all stages of history the media have played a significant role in building and maintaining confidence in ourselves, in institutions and in the continuity of everyday life, as essential components of the experience of reality (Innis, 1951; Silverstone, 1999).

The media are "abstract systems" (Giddens, 2002) in which we place trust, reinforcing our willingness to trust other abstract systems and each other, but if this trust is shown to be psychologically unsatisfactory, this depends on what is assessed against it and on those sources of trust (including personal trust) that are available or have been available over time. This happens because mediated and non-mediated experiences intertwine, participation and representation bind together shaping and unifying public and private space. 


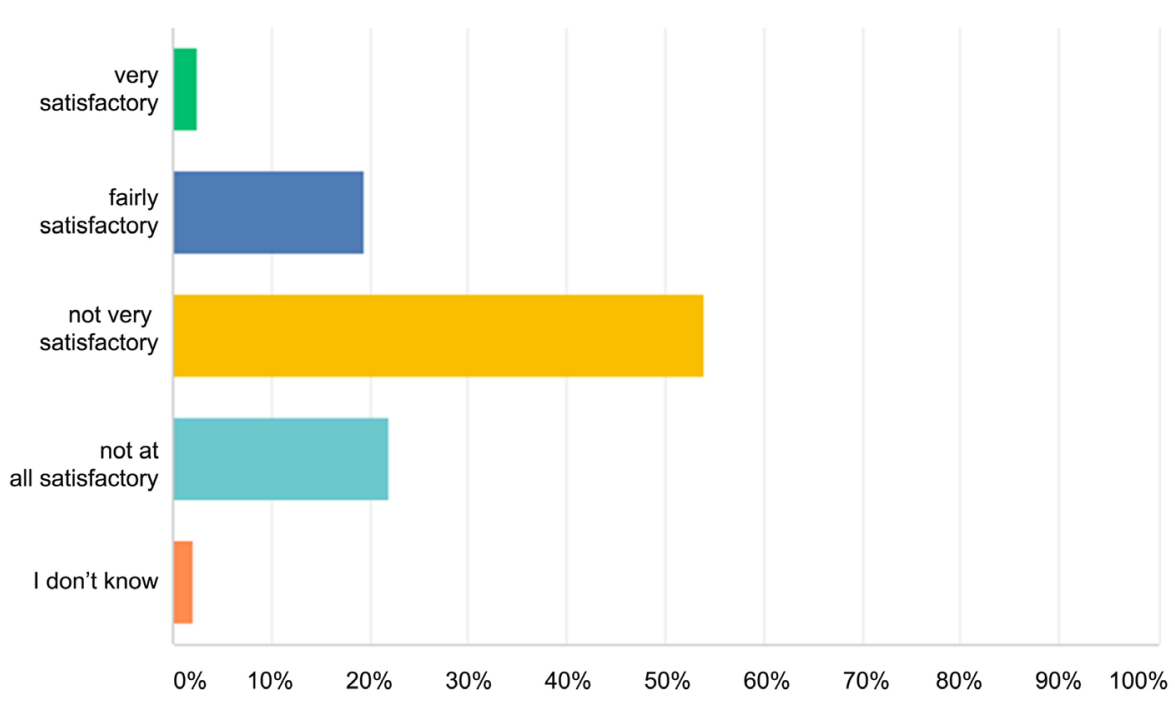

Figure 7. How do you consider information on immigration in the main Italian media?

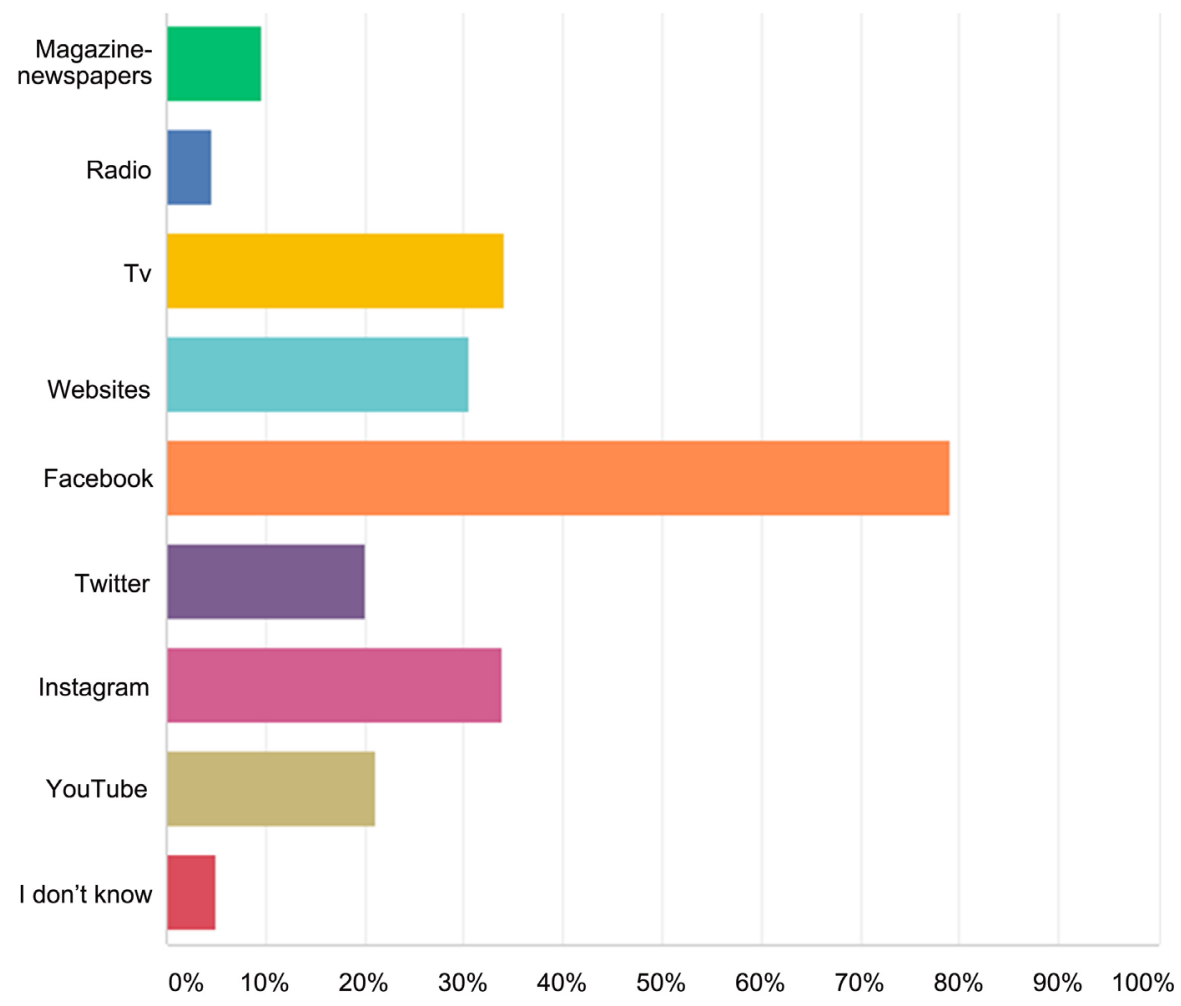

Figure 8. Which communication spaces do you think contain more verbal violence and misinformation?

In the following data this concept emerges when students are asked if the presence of blogs, online groups, forums, pages and official (and not) "pro-immigration" information spaces can positively contribute to create new forms of solidarity on the web and/or explain the migration phenomenon more correctly.

$71.22 \%$ of students believe that this is possible mainly because the characteristics of the web allow "access to different news" and "the immediate comparison 


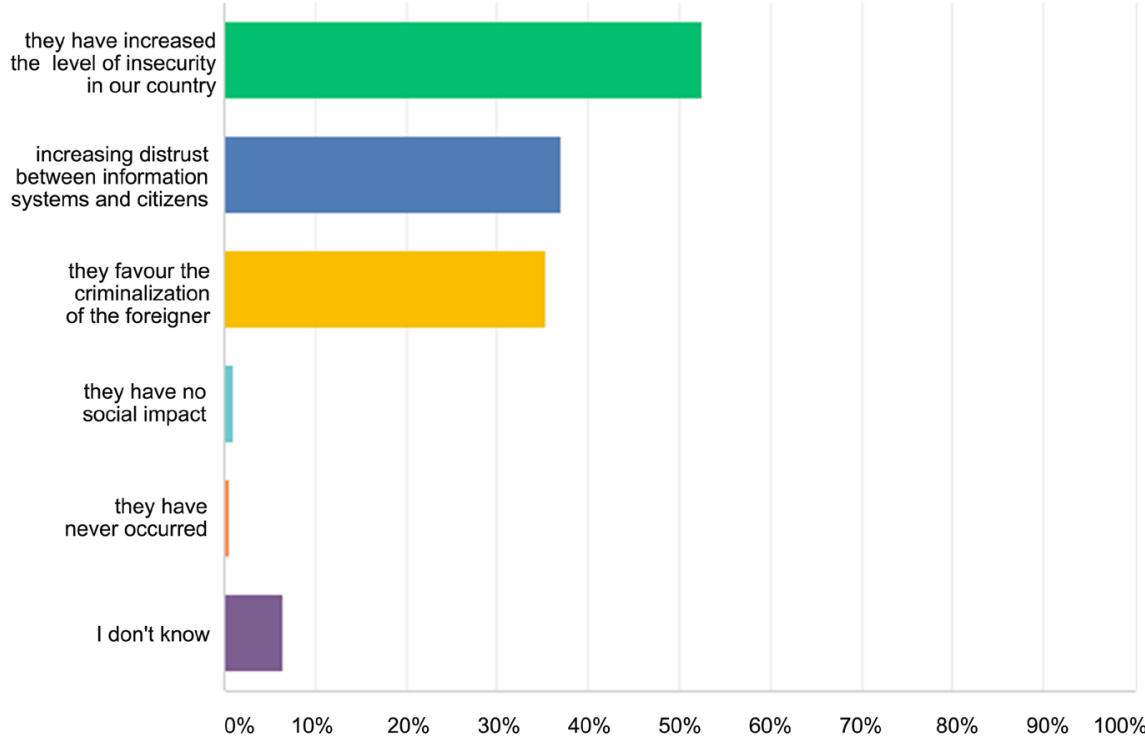

Figure 9. What are the consequences of fake news (online buffaloes) or hate speech on the immigration phenomenon?

of sources" (65.40\%), "favours the meeting with subjects of different cultures" for $38.86 \%$ (Figure 10, Figure 11).

Online hatred and misinformation are the two factors that have undermined insecurity and distrust in media spaces and this is because, paraphrasing Giddens (2002), we are living a new world of global communication that in its plurality cannot hide the continuous presence of important differences and conflicts.

However, a positive attitude and awareness seem to emerge in the interviewees: to put trust in the media and information today means to use the net in a responsible way, without moving away from media spaces, but living them daily with the risk of making mistakes, cultivating new communication information management skills and trying to foresee the consequences of our communication in the public space (Sustein, 2009; SWG, 2017).

In the information society, the absence of information would be considered an "immense deprivation" (Silverstone, 1999), but it is also true that information in itself has no value, what counts is knowledge, understanding the latter (in this specific context) as a synonym of "media competence": the ability to know how to read and understand what we see and hear.

\section{Institutions, Communication and Migration Flows}

In the last fifteen years Europe has acquired a central position in the global migration geography; due to issues related to geographical location and socio-demographic structure, the continent has been and is, at the same time, exposed to spontaneous migration and in need of selectively planned flows (Ducci, 2012).

The difficulty of matching the migratory reality with the aspirations and 


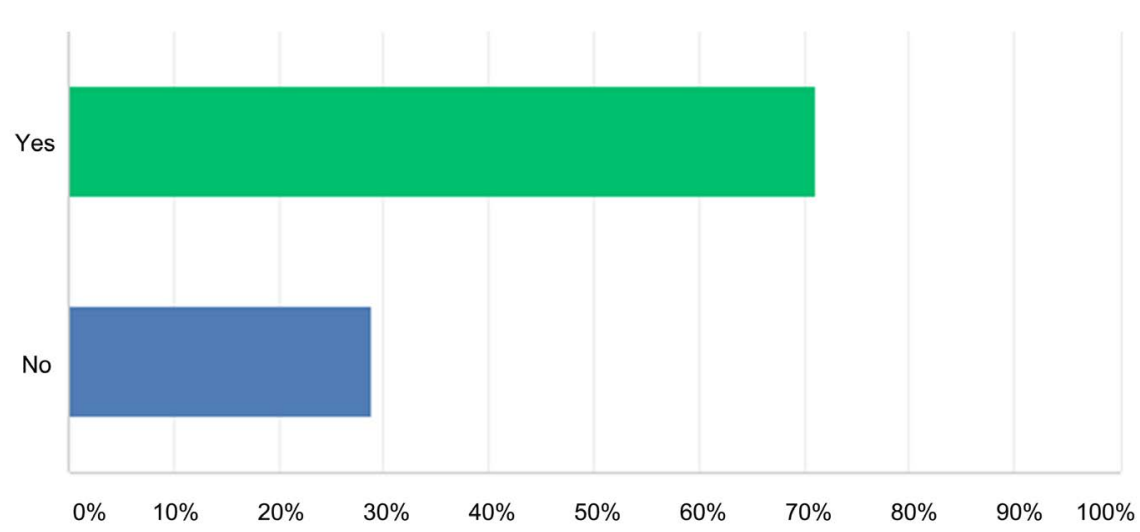

Figure 10. Could the presence of online groups, events, forums, blogs and pro-immigration web pages help to better explain the migration phenomenon and create new forms of solidarity?

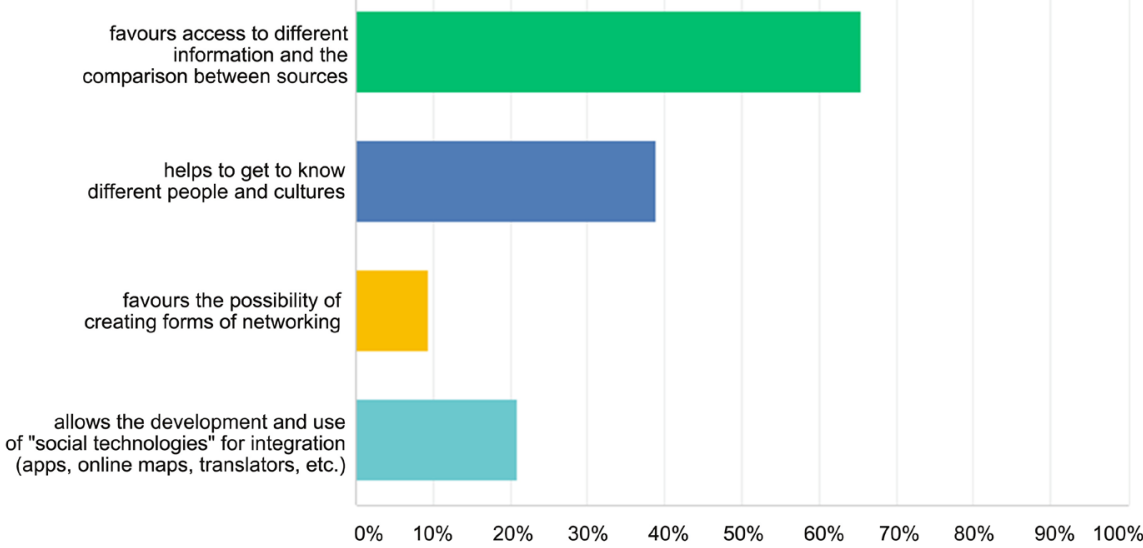

Figure 11. If you answered yes, motivate your answer.

structural needs represents one of the central challenges for the future of European societies and institutions: communication is, in fact, functional to the information needs and the demand for transparency made by citizens. It is necessary, above all, for the promotion of service communication, aimed at guaranteeing efficiency and effectiveness of the action promoted by the European institutions and, at the same time, it is indispensable to enhance European citizenship and make the community aware of civic sense (D'Ambrosi, Papakristo, \& Polci 2018; Buoncompagni, 2020).

The opportunities offered by the Net and technological developments have increased the quantity and quality of institutional and European information, favouring the use of sites, blogs, in-depth databases, facilitating a more active participation of readers, thanks to the interactive nature of the new media and the possibility for users to play the unprecedented role of producers and distributors of online content; however, there are still many difficulties for editorial offices to adapt information as much as possible to the decision-making times of the various public spheres (European and national) and its impact on local information (Buoncompagni, 2020). 
This latter aspect in particular also deeply affects the migration issue.

Recognising the immigrant population no longer as a problem to be tackled, but as an ineliminable component of contemporary society to be studied, communicated with and managed in a strategic and responsible way, could perhaps represent the first step towards a new vision of the immigration phenomenon, renewing first of all the information languages and media tools.

In Europe, media "errors" have been almost the same as those found in Italy; in this regard, the Ethical Journalism Network has carried out an analysis on the media coverage of migration inherent to the communication activity in the European Union in 14 countries around the world.

The study shows how journalists are often unable to report the news in its entirety, but fall into propaganda and political formats: for example, the tone of the messages analysed often recalls that of hate speeches, anti-immigrant statements that fuel growing public concern.

This can also be seen in recent political changes in countries of reference for public opinion, such as Brexit (UK) and Donald Trump's victory in the 2016 presidential elections in the United States, which have contributed to a further propaganda escalation, turning migration and terrorism into a key issue for any election campaign.

For these reasons, in the third section of the questionnaire specific questions were addressed to the survey participants, such as: "How do you consider the ways in which European institutions have communicated the migration phenomenon so far?" and "What should national institutions (Municipalities, Regions, Ministries...) do to tackle the migration problem?".

With regard to the first question, there is a clear agreement between the students' opinion and what has just been described about the journalistic and institutional communication of migration: $54.69 \%$ consider the communication on migration issues by the European institutions unsatisfactory, $32.73 \%$ consider it not at all satisfactory (Figure 12).

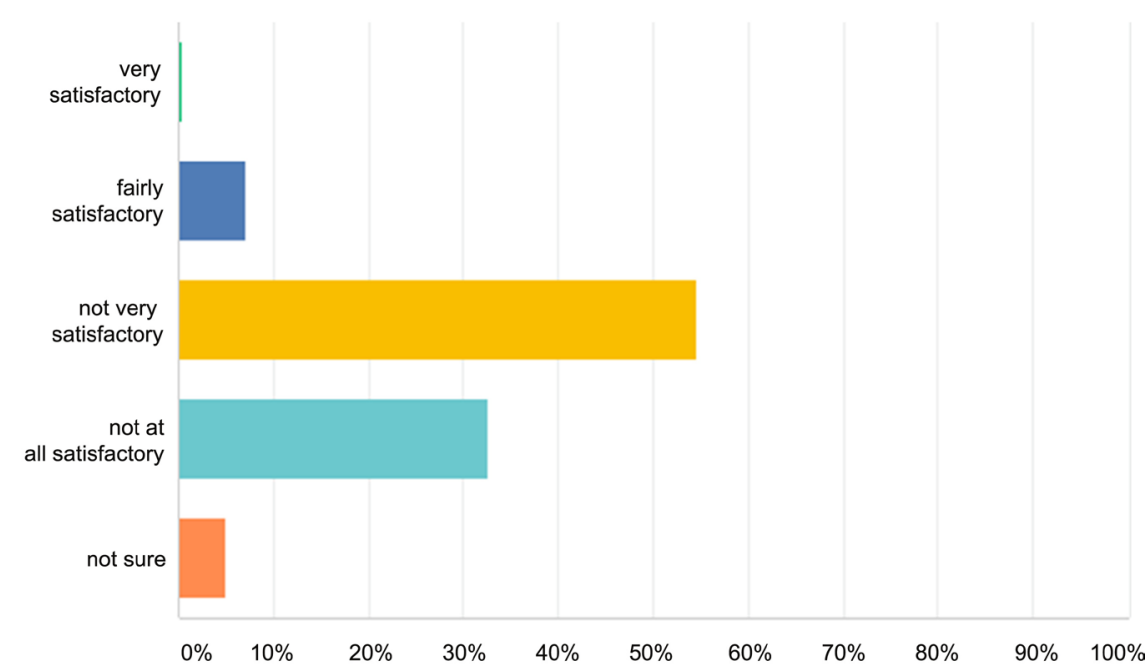

Figure 12. How do you consider the ways in which the European institutions have communicated the migration phenomenon so far? 


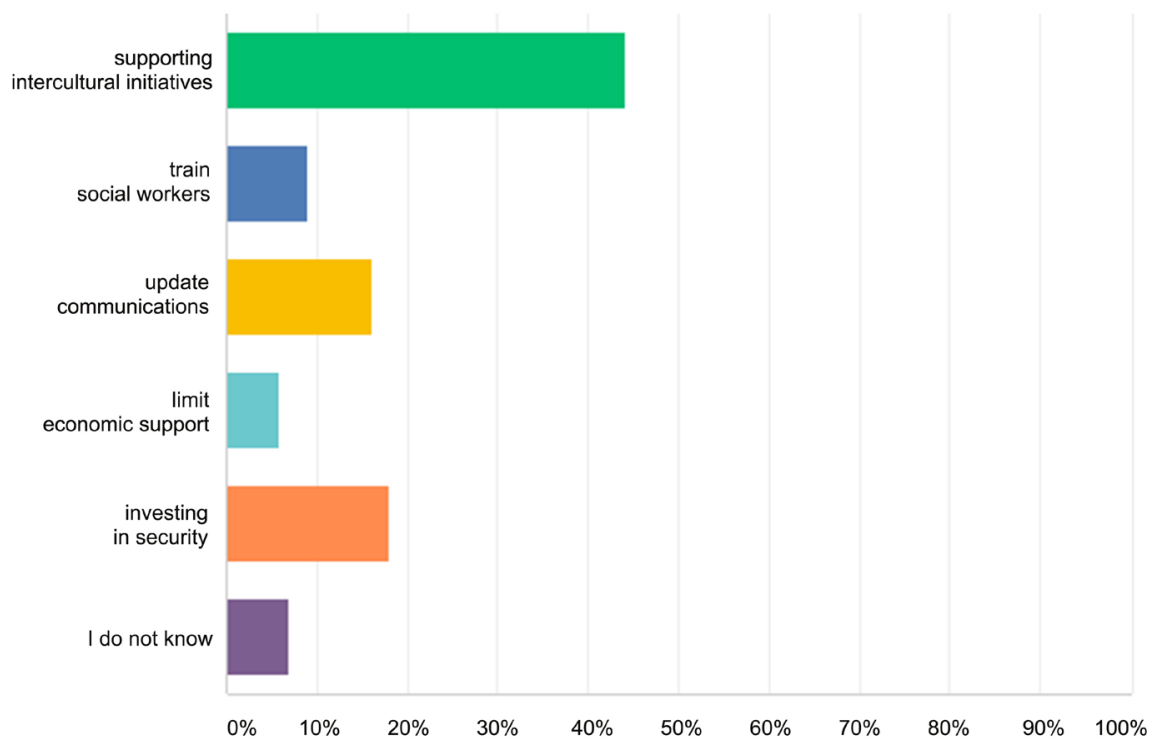

Figure 13. Secondly, what should institutions (Municipalities, Regions, Ministries...) do to tackle the problem of immigration?**

Subsequently the interviewees were asked how, in their opinion, this communication problem could be reduced, proposing a series of contrasting interventions of a political-social and communicative nature.

"Supporting intercultural communication initiatives (e.g. research, media education...) is the option that received the most responses (44.24\%), while $16.19 \%$ believe that it is more useful to "constantly update the citizen on initiatives and projects implemented and in progress", while $17.99 \%$ point out that a greater investment should be made in support of security policies for greater control of law enforcement on the territory (Figure 13).

The communicative dimension is at the basis of any public discourse and policy related to the migration phenomenon; a phenomenon that especially in recent years has launched a major challenge for Italy and Europe, that of building a more inclusive public communication and more balanced information.

\section{Conclusion}

There is an increasingly urgent need to develop and better define communication skills in the journalistic, social and institutional fields in order to intercept the needs of the immigrant population and plan/implement public policies based on respect and enhancement of diversity. The choices that are made in terms of communication and policies for immigrants are crucial to build solid foundations and foster real social integration. The relationship between third country nationals and the host society is based on the latter's ability to guarantee migrants ways of participating in the social, cultural and economic life of a country, but this "reciprocity pact" foresees that on the other hand migrants themselves actively participate in the integration process, respecting the values and norms of the host culture, without giving up their own identity (Buoncompagni, 


\section{D’Ambrosi, 2020).}

In this way, a new communicative-media environment would be defined where it is possible to draw on specific identity resources that favour the interaction of different cultural experiences and create new forms of narration of diversity and otherness.

It becomes fundamental at this point to perceive the media (starting from the local ones) both as a basic formation of the multicultural society, impressed in our humanity and able to influence it in an incisive way, and as strategies of resistance to the phenomena of communicative, cultural and social marginalization of immigrants. At a local, national and European level, it is possible to identify a further challenge that of building institutional communication is able to guarantee modalities and spaces for relations with the increasingly mobile citizens through the new digital technologies.

Communicating immigration is a specific competence that public institutions should acquire with the aim of rebalancing certain rather distorted media narratives.

Public communication, in fact, can represent a strategic channel to govern migration flows and the inclusion of foreign subjects, promoting as much as possible an effective cohesion, starting from Municipalities and Regions that, in this process of creation and strengthening of the community, are fundamental elements as they are closer to citizens and more aware of individual realities.

Within these realities, the media have a strategic importance as they are called to support institutional action and to exercise a responsible narrative action aimed at promoting dialogue between cultures and providing balanced information.

The care of information on immigration, to and from the media system, has become an urgent necessity for the institutions and the way of understanding interculturality within a community can be seen in the relationship between citizens and public subjects, between institutional bodies and those responsible for communication.

The insecurity of the population is reflected (and is influenced) by the media, its images and metaphors that still portray immigration in terms of "invasion" and this format of information attracts and involves the public emotionally by increasing media consumption.

Getting rid of stereotypes partly created by the spectacular media narrative seems almost impossible: the use of expressions such as "emergency" or "waves", which refer to the idea of an invasion of migrants, contributes to representing immigration as a dangerous or transitory event, disconnected from the real dynamics of migration flows.

\section{Conflicts of Interest}

The author declares no conflicts of interest regarding the publication of this paper. 


\section{References}

Affricott, J. (2018). È iniziata la caccia al nero. I fatti di Macerata visti da una nera italiana. https://www.vice.com/it/article/8xd955/luca-traini-macerata-razzismo

Ambrosini, M. (2011). Sociologia delle migrazioni. Bologna: il Mulino.

Bauder, H. (2011). Immigration Dialectic: Imagining Community, Economy and Nation, Toronto: University of Toronto Press. https://doi.org/10.3138/9781442687196

Beck, U. (2006). The Cosmopolitan Vision. Cambridge: Polity.

Buoncompagni, G. (2019). Connectivity and Global Information. The Digital Side of Immigration in Socioscapes. International Journal of Societies, Politics and Cultures, 1, 223-234.

Buoncompagni, G. (2020). Cyber-Risk, Cyber-Migration. For a New Human Geography and Security. Sicurezza, Terrorismo, Società, 11, 157-177.

Buoncompagni, G., \& D’Ambrosi, L. (2020). Hate Speech Towards Migrants. In G. La Rocca, \& J. M. Torvisco (Eds.), Technological and Digital Risk: Research Issues (pp. 177-190). Pieterlen and Bern: Peter Lang Publishing.

D’Ambrosi, L., Papakristo, P., \& Polci, V. (2018). Social Media and Gender Violence: Communication Strategies for a "New Education". Italian Journal of Sociology of Education, 10, 76-89.

Ducci, G. (2012). La comunicazione pubblica e la sfida dell'interculturalità. Franco Angeli: Milano.

Giddens, A. (2002). Runaway World: How Globalization Is Reshaping Our Lives. London: Profile Books.

Gillespie, T. (2018). Custodians of the Internet: Platforms, Content Moderation, and the Hidden Decisions That Shape Social Media. London: Yale University Press.

Innis, H. (1951). The Bias of Communication. Toronto-Buffalo: University of Toronto Press.

Kymlicka, W. (2012). Multiculturalism: Success, Failure, and the Future. Washington DC: Migration Policy Institute.

Lippmann, W. (1922). L'opinione pubblica. Roma: Donzelli.

Orsini, A. (2019). Viva gli immigrati. Gestire la politica migratoria per tornare protagonisti in Europa. Milano: Rizzoli.

Palidda, S. (2011). Racial Criminalization of Migrants in the 21st Century, Farnham: Ashgate.

Prensky, M. (2013). La mente aumentata. Dai nativi digitali alla saggezza digitale. Trento: Erickson.

Quattrociocchi, W., \& Vicini, A. (2017). Misinformation. Guida alla società dell'informazione e della credulità. Milano: Franco Angeli.

Silverstone, R. (1999). Why Study the Media? London: Sage.

Sustein, R. C. (2009). On Rumors: How Falsehoods Spread, Why We Believe Them, What Can Be Done. New York, NY: FSG.

SWG (2017). Hate speech e fake news tra cittadini, lavoratori e dirigenti. Trieste.

Van Dijk, T. A. (2003). Ideologie. Roma: Carocci.

Ziccardi, G. (2016). L'odio online. Milano: Raffaello Cortina. 